\title{
DELTAS DOMINADOS POR ONDAS: CRÍTICAS ÀS IDÉIAS ATUAIS COM REFERENCIA PARTICULAR AO MODELO DE COLEMAN \& WRIGHT
}

\author{
JOSÉ MARIA LANDIM DOMINGUEZ*
}

\begin{abstract}
WAVE-DOMINATED DELTAS: CRITIQUE TO CURRENT IDEAS WITH PARTICULAR REFERENCE TO COLEMAN \& WRIGHT'S MODEL. The study of coastal evolution of strandplains associated with major rivers along the eastern coast of Brazil, considered to be typical wave-dominated deltas, has shown mat existing models of deltaic sedimentation (e.g. Coleman \& Wright) can not properly explain the Quaternary evolution of these areas. Deltaic sedimentation models in wave-dominated settings have drawn heavily from Holocene examples whose coastal evolution were poorly understood (e.g. São Francisco, Senegal, Nile rivers). Circularity of reasoning and uncritical application of principles of deltaic sedimentation to those areas have men resulted hi a series of misconceptions. These misconceptions are discussed in the light of information from the eastern coast of Brazil. The discussion focuses in three aspects. Firstly, the existing modelsdo not accountfor changesin sea level which have played a fundamental role during the evolution of the Brazilian strandplains. Secondly it is traditionally assumed mat dip-feeding is the predominant way of introduction of sediment to the strandplain. For the Brazilian areas strike-feeding by longshore currents played an important role in introducing sediments to the strandplain. In some cases the volume of sediments introduced by longshore currents greatly surpassed the volume of riverborne sediment. Thirdly, the existing models assume mat autocyclic processes are the most important in controlling channel switching at the strandplain. In the eastern coast of Brazil external forcing by high frequency Holocene sea level changes was the main factor in controlling channel switching. Finally it is suggested the use of the term delta to be restricted to those coastal accumulation forms in which riverine processes are the solely responsible for the observed fades distribution. Such attitude would certainly avoid much of the confusion that permeates the literature today.
\end{abstract}

Keywords: Deltaic sedimentation, fades models, Quaternary.

\begin{abstract}
RESUMO O estudo da evolução quaternária de planícies de cordões litorâneos associados às maiores desembocaduras fluviais da costa leste do Brasil, consideradas como típicos deltas dominados por ondas, demonstra que os modelos existentes de sedimentação deltaica (e.g. Coleman \& Wright) não explicam de forma apropriada a evolução quaternária dessas áreas. Modelos de sedimentação deltaica em ambientes dominados por ondas se basearam em exemplos holocênicos cuja evolução, à época do desenvolvimento desses modelos, era pobremente compreendida (e.g. Rios São Francisco, Senegal e Nilo). Apriorismo, raciocínio circular e aplicação não crítica de princípios de sedimentação deltaica para estas áreas pouco conhecidas, resultaram em concepções errôneas. Estas concepções errôneas são discutidas à luz de informações obtidas pelo estudo da evolução quaternária da costa leste do Brasil. A discussão focalizará três aspectos principais: 1. os modelos existentes não levam em conta as variações do nível do mar, as quais desempenharam um papel fundamental durante a evolução das planícies de cordões litorâneos brasileiras associadas a desembocaduras fluviais; 2. supõe-se tradicionalmente que alimentação transversal (dip-feeding) 6 o modo predominante de introdução de sedimentos em planícies de cordões litorâneos associadas a desembocaduras fluviais. No caso dos exemplos brasileiros, a alimentação longitudinal (strike-feeding) por correntes longitudinais geradas por ondas desempenhou um papel importante na introdução de sedimentos arenosos para essas planícies. Em alguns casos, o volume de sedimentos introduzidos por correntes longitudinais comprovadamente suplantou o volume de sedimentos fluviais; 3. os modelos de sedimentação deltaica existentes assumem que processos autocíclicos foram os mais importantes a controlar mudanças na posição dos canais fluviais (channel switching), nas planícies de cordões litorâneos. Na costa leste do Brasil, elementos forçadores externos (alociclicidade), tais como subidas do nível relativo do mar, foram os principais fatores a controlar mudanças na posição dos canais fluviais. Finalmente, sugere-se que o uso do termo "delta" seja restrito àquelas acumulações costeiras nas quais processos fluviais são os únicos responsáveis pela distribuição de fades observada. Tal atitude certamente evitaria muito da confusão que permeia atualmente a literatura.
\end{abstract}

Palavras-chaves: Sedimentação deltaica, modelos de fades, Quaternário.

INTRODUÇÃO No início e meados da década de 70, J.M. Coleman e L.D. Wright publicaram uma série de trabalhos (Coleman \& Wright 1971, 1975, Wright \& Coleman 1972, 1973) que muito influenciaram nossas idéias sobre sedimentação deltaica. Esses autores, baseados em trabalho anterior de Fisher et al. (1969), desenvolveram um modelo classificatório bastante conhecido (a este respeito veja também Galloway 1975), de acordo com o qual a morfologia e estrutura tridimensional das acumulacões deltaicas são controladas por fatores tais como descarga fluvial, amplitude das marés e energia das ondas. Infelizmente, estes esquemas de classificação basearam-se em exemplos holocênicos, cuja evolução, ao tempo em que aqueles trabalhos foram escritos (e até mesmo agora), não era bem conhecida (e.g. Rios São Francisco, Senegal e Nilo). Esses autores cometeram, portanto, um erro básico no método científico, ou seja, o de que a sistematização em ciência não deve ser feita apriori. Teorias, classificações e definições não devem ser formuladas aprioristicamente com base em divagações abstratas, para depois então se buscar na natureza fatos que as confirmem (Chamberlin 1890, ed. 1965).

Apriorismo, raciocínio circular e aplicação indiscriminada desses modelos de sedimentação deltaica em seqüências costeiras dominadas por ondas de idade moderna e mais antigas, resultou em interpretações errôneas.

O objetivo deste trabalho é o de comentar algumas destas interpretações errôneas à luz de informações disponíveis para a costa leste do Brasil, incluindo planícies quaternárias costeiras como aquela associada, à foz do Rio São Francisco. Informações publicadas na literatura, particularmente aquelas relativas à planície costeira associada à foz do Rio Senegal 
(África Ocidental), também serão utilizadas.

Este trabalho se concentra naqueles aspectos diretamente relacionados a ambientes marinhos do tipo dominado por ondas como definido em Heward (1981). A discussão focalizará três importantes aspectos da sedimentação em ambientes dominados por ondas, os quais não foram incorporados de maneira apropriada aos modelos de sedimentação deltaica; 1. variações do nível do mar, 2. alimentação transversal versus alimentação longitudinal e 3. autociclicidade versus alociclicidade.

VARIAÇÕES DO NÍVEL DO MAR E SEDIMENTAÇÃO DELTAICA Até muito recentemente, pensava-se que o nível do mar teria subido continuamente em todas as regiões do globo durante os últimos $5 \mathrm{ka}$. Embora existissem evidências geológicas e datações pelo método do radiocarbono que emprestavam apoio a outras histórias de variações do nível do mar (por exemplo nível do mar oscilando ou em abaixamento), as mesmas eram usualmente descartadas como sendo exóticas. Desse modo, não causa surpresa que Coleman \&
Wright (1971, 1975), embora tenham analisado a influência de pelo menos 400 diferentes parâmetros na geometria de corpos arenosos de origem deltaica, não tenham se preocupado com os efeitos das variações do nível do mar no desenvolvimento de sistemas deltaicos.

Mais recentemente, estudos da reologia da crosta terrestre (Walcott 1972, ChapelI 1974, Clark et al. 1978) e a introdução do conceito de que a configuração do geóide teria mudado ao longo do tempo (Mõrner 1976) levaram ao reconhecimento de que a resposta do nível do mar à última deglaciação não necessitava ser globalmente uniforme, e diferenças regionais deveriam ser esperadas. Atualmente, é bem aceito o fato de que nenhuma curva de variações do nível do mar pode ser verdadeiramente eustática, possuindo apenas uma validade local (Newman et cá. 1980, Kidson 1982).

Á história das variações holocênicas do nível do mar ao longo da costa leste do Brasil é caracterizada por um nível cerca de $5 \mathrm{~m}$ mais alto que o nível atual, por volta de $5,1 \mathrm{ka}$ (Martin et al. 1980, Suguio et al. 1980). O abaixamehto do nível do mar desde aquela época não foi regular, mas interrom-

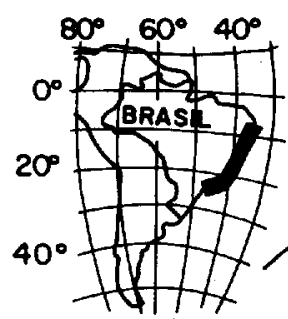

\section{BACIA DE DRENAGEM}
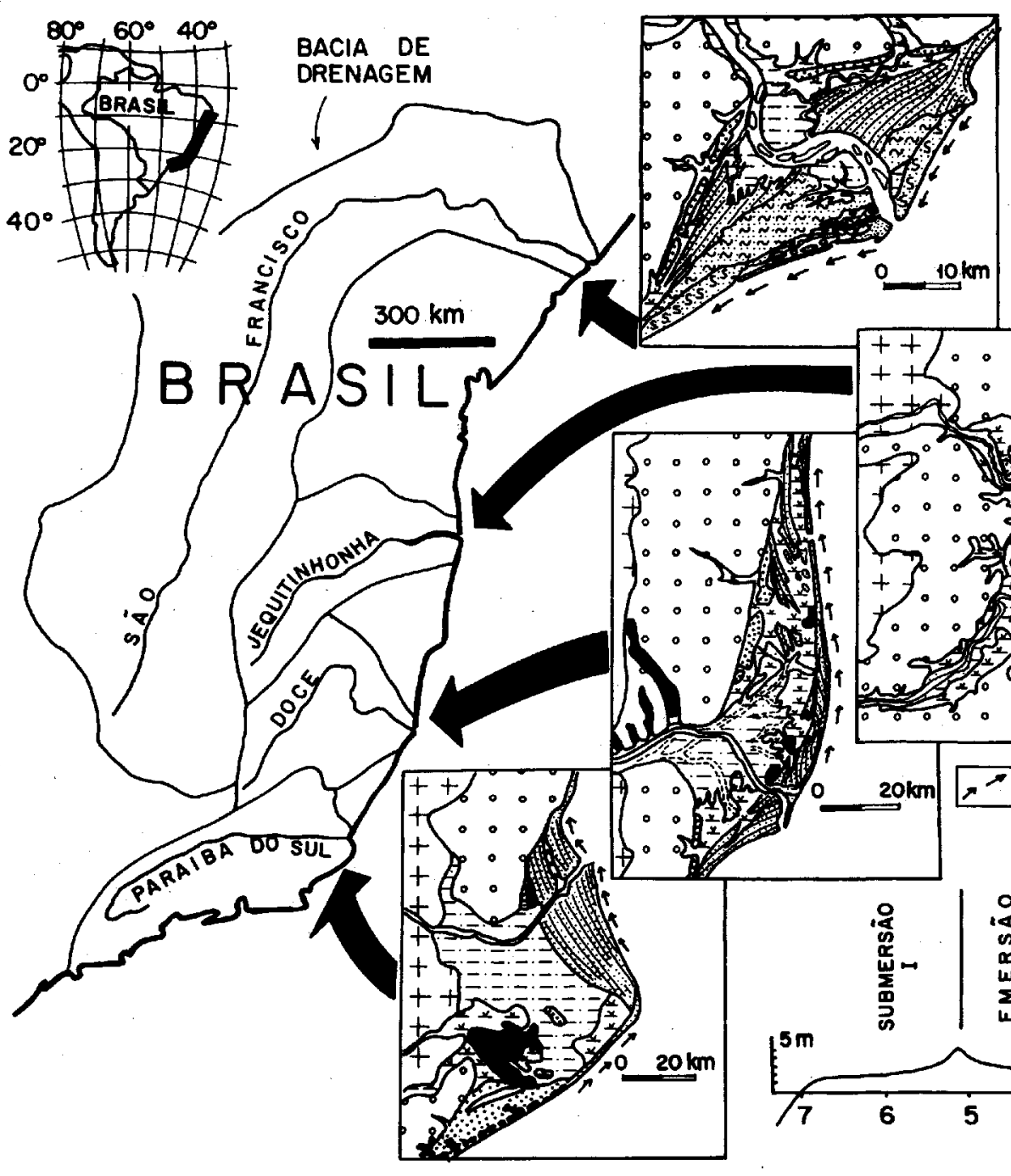

Pantano água doce

$\because \because 0$ MANGUE

\section{E: $:$ F FLUVIAL}

CORDÕES LLTORÂNEOS

HOLOCENICOS

O: CORDÖES LITORÂNEOS

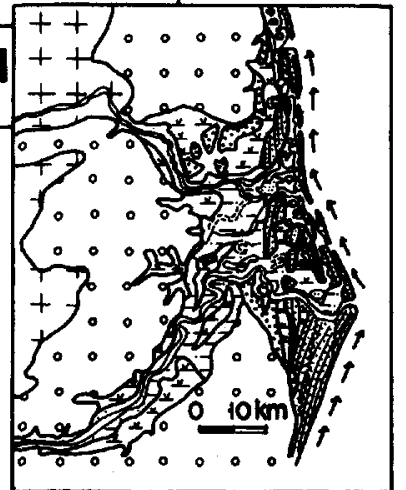

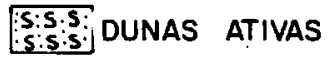

DUNAS INATIVAS

:0: FM. BARREIRAS

++ PRE-CAMBRIANO

$\therefore=:-P$ PALEO-CANAL

\section{LAGO}

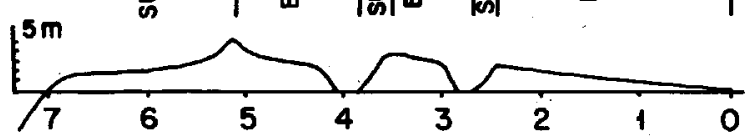

Figura 1 - Localização e mapas geológicos simplificados das planícies de cordões litorâneos associadas às desembocaduras dos Rios São Francisco, Jequitinhonha, Doce e Paraíba do Sul (mapas segundo Dominguez et al. 1981). No canto inferior direito está representada a curva de variações do nível relativo do mar, durante o Holoceno, para a costa leste-sudeste do Brasil (segundo Martin et al. 1980)

Figure 1 - Location and simplified geologic maps of the beach-ridge plains associated with the Sab Francisco, Jequitinhonha, Doce and Paraíba do Sul river mouths (maps after Dominguez et al. 1981). The relative sea level curve valid for the eastern-southeastern coast of Brazil is shown on the lower right corner (after Martin et al. 1980) 
pido por oscilações de alta freqüência com amplitudes de 2 a 3 $\mathrm{m}$ atuando em escala de tempo de não mais de 200 a 300 anos (Fig. 1). Como resultado, a história das variações holocênicas do nível do mar para a costa leste do Brasil pode ser subdividida em três fases principais de submersão $(7,0 \mathrm{ka}-5,1 \mathrm{ka}$, $3,8 \mathrm{ka}-3,5 \mathrm{ka}$ e $2,7 \mathrm{ka}-2,5 \mathrm{ka}$ ) associadas a três fases de emersão $(5,1 \mathrm{ka}-3,8 \mathrm{ka}, 3,5 \mathrm{ka}-2,7 \mathrm{ka}$ e $2,5 \mathrm{ka}$ até o presente) (Fig. 1).

Extensas planícies de cordões litorâneos ocorrem associadas as desembocaduras dos quatro maiores rios que desembocam na costa leste do Brasil (Fig. 1). A integração da história regional das variações do nível do mar, com mapeamento detalhado e datações pelo método do radiocarbono de depósitos de cordões litorâneos, lagunares e fluviais presentes nestas planícies, suportam fortemente a interpretação de que a história das variações do nível do mar desempenhou um papel fundamental na determinação dos estilos de sedimentação costeira (Suguio et al. 1984, Dominguez 1984, Dominguez et al. 1981, 1987). Estes estudos mostram que, sob condições de elevação do nível do mar, sistemas de ilhas barreiras/lagunas são o modo dominante de sedimentação. Os rios constróem deltas em ambientes protegidos, tais como lagunas, baías e estuários. Planícies de cordões litorâneos são visivelmente ausentes. Esta é a morfologia que caracteriza, por exemplo, a costa atlântica dos Estados Unidos e a costa oriental do Golfo do México, nas quais durante os últimos $5 \mathrm{ka}$ o nível do mar tem subido continuamente. Em contraste, descidas do nível do mar impõem condições altamente desfavoráveis à gênese e sobrevivência de sistemas de ilhas barreiras/lagunas. Lagunas e baías tornam-se rapidamente emersas durante esses episódios. As planícies de cordões litorâneos progradam rapidamente. Esse é o caso da costa leste do Brasil onde ilhas barreiras separadas do continente por uma laguna são hoje virtualmente ausentes, embora abundantes no passado. A evolução quaternária costeira das planícies de cordões litorâneos situadas na costa leste do Brasil é sumariada a seguir (Fig. 2).

(A)

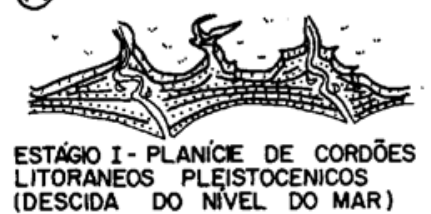

(C)

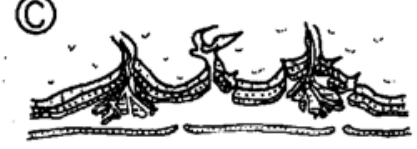

ESTAGO III - DELTAS INTRALAGUNARES

$$
\begin{aligned}
& \text { \# PANTANO ÁGUA DOCE } \\
& \Xi: \text { FluVIAL }
\end{aligned}
$$

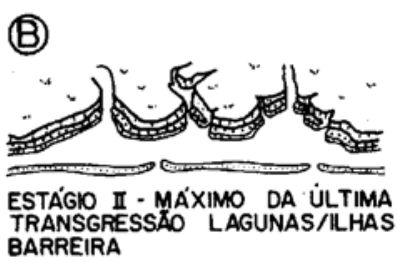

(D)

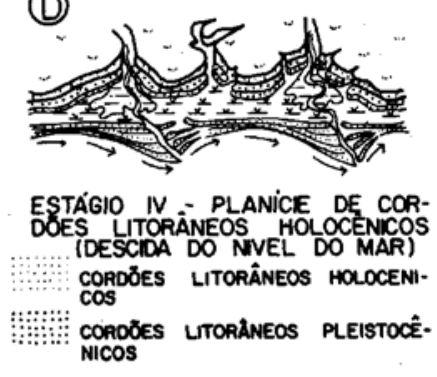

Figura 2 - Esquema evolutivo, durante os últimos $120 \mathrm{ka}$ das planícies de cordões litorâneos associadas às desembocaduras dos Rios São Francisco, Jequitinhonha, Doce e Paraíba do Sul (segundo Dominguez et al. 7957;

Figure 2 - Evolutionary scheme for the beach-ridge plains associated with the São Francisco, Jequitinhonha, Doce and Paraíba do Sul river mouths during the last $120 \mathrm{ka}$ (after Dominguez etal, 1987)

ESTÁGIO I Construção de planícies de cordões litorâneos de idade pleistocênica associadas ao máximo da útima grande transgressão pleistocênica (120ka) e o episódio regressivo se- guinte. Estas planícies formam o arcabouço sobre o qual os estágios posteriores vão atuar (Fig. 2a). ESTAGIO II A transgressão holocênica erodiu e afogou parcialmente às planícies de cordões litorâneos pleistocênicas. Pela ocasião em que o máximo da transgressão holocênica foi alcançada $(5,1 \mathrm{ka})$, extensos sistemas de ilhas-barreiras/lagunas foram formados. Os vales aluviais também afogados, dando origem a estuários e baías (Fig. 2b). ESTÁGIO III Nos locais onde grandes rios estavam presentes, os mesmos construíram deltas dentro de baías, nas cabeceiras de estuários ou em lagunas (Fig. 2c).

ESTÁGIO IV O abaixamento do nível do mar que se seguiu ao máximo da transgressão holocênica $(5,1 \mathrm{ka})$ favoreceu a progradação da linha de costa, o que resultou na construção das planícies de cordões litorâneos holocênicas (Fig. 2d). Esta descida do nível do mar também expôs sedimentos lagunares e estuarinos. Os rios começaram então a desembocar diretamente na plataforma interna. Os efluentes fluviais atuaram* como molhes, retendo a barlamar (updrifi) da desembocadura fluvial os sedimentos transportados pela deriva litorânea (o "Efeito de Molhe", Dominguez et al. 1983). Este aspecto será discutido com mais detalhe.

Michel (1968), trabalhando na planície costeira associada à foz do Rio Senegal (África Ocidental), considerada por Coleman \& Wright (1975) como um típico delta dominado por ondas, elaborou para esta região um modelo evolutivo bastante semelhante àquele descrito para as planícies de cordões litorâneos da costa leste do Brasil (Fig. 3). Interessante notar que as curvas de variação do nível do mar durante o Holoceno, construídas para a costa do Senegal, também mostram a existência de uma história de variações do nível do mar semelhante àquela experimentada pela costa leste do Brasil, incluindo a presença de níveis de mar holocênicos superiores ao atual (Faure \& Hebrard 1973).

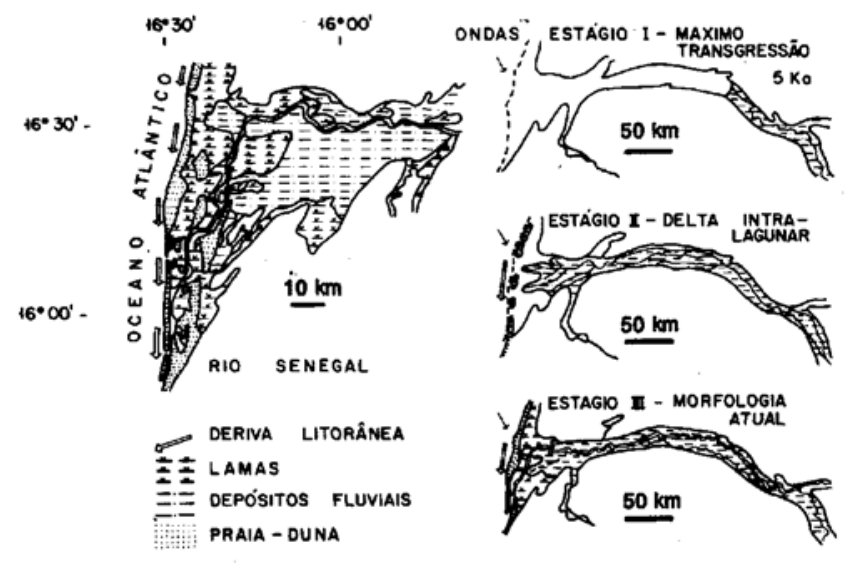

Figura 3 - Mapa geológico simplificado e esquema evolutivo durante os últimos 5 ka da planície do Rio Senegal (África Ocidental) (modificado de Michel 1968)

Figure 3 - Simplified geologic map and evolutionary scheme for the Senegal river plain (Western Africa), during the last $5 \mathrm{ka}$ (modified form Michel 1968)

Torna- se evidente, portanto, que a morfologia e a distribuição de fácies nos chamados deltas dominados por ondas não são controladas exclusivamente pela interação entre a energia das ondas e a descarga fluvial, como sugerem os modelos existentes de sedimentação deltaica (Fisher et al. 1969, Coleman \& Wright 1975, Galloway 1975). A história das variações do nível do mar durante o Quaternário exerceu um papel fundamental na determinação dos estilos de sedimenta- 
cão e, em conseqüência, deve ser levada em consideração no desenvolvimento de modelos de sedimentação costeira (Suguio et al. 1984, Dominguez 1984, Dominguez et al. 1987).

Um exemplo no qual erros grosseiros foram cometidos, por se ignorar o papel das variações do nível do mar na sedimentação costeira, é fornecido por Fisher (1969) em relação aos depósitos quaternários associados à desembocadura do Rio Apalachicola (noroeste da Flórida, EUA). Schnable \& Goodell (1968) mapearam essa área e identificaram terraços de cordões litorâneos de idade pleistocênica, separados de um conjunto de ilhas barreiras por uma extensa baía. O Rio Apalachicola constrói atualmente um delta na cabeceira dessa baía (Fig. 4a). Fisher (1969) interpretou o mapa de Schnable \& Goodell (1968) à luz dos novos conceitos de sedimentação deltaica (Fig. 4b). Uma rápida comparação entre os dois mapas (Fig. 4) mostra os erros grosseiros cometidos por Fisher (1969), que afirma: "Dotted Unes indicate the inferred original extent of main distritutaries and extent of previous progradation. Apparently, sand storage of prograded units was slight with marine processes reworking and depositing much of the sediment input as a series of coastal barriers". Como se vê, Fisher (1969) concluiu que as ilhas barreiras são o resultado do retrabalhamento, pelos proocessos marinhos, de sedimentos oriundos do Rio Apalachicola. Em verdade, a presente distribuição de fácies nada mais é do que o efeito de um nível de mar em elevação que tem afetado a costa do Golfo do México nos últimos $5 \mathrm{ka}$.

Finalmente, e em relação a este mesmo aspecto, é intrigante se constatar que nos mapas geológicos do delta do Rio Nilo (Fig. 6, em Wright \& Coleman 1973) apenas os depósitos praiais associados à Unha de praia atual estão representados. Se o Nilo é realmente um delta do tipo dominado por ondas, e a energia das ondas sempre exerceu um papel dominante na construção da planície deltaica, seria de se esperar que depósitos praiais também ocorressem no interior da planície costeira, o que aparentemente não é verdadeiro. Talvez algum outro fator até então não considerado (e.g. as variações do nível do mar) tenha exercido uma importante influência no controle da distribuição de fácies na planície costeira associada à desembocadura do Rio Nilo. Seria o Nilo um exemplo de rio que construiu um delta intralagunar e só agora começa a alcançar o mar aberto?

ALIMENTAÇÃO TRANSVERSAL VERSUS ALIMENTAÇÃO LONGITUDINAL Desde que foi usado por Heródoto para descrever a terra aluvial entre os dois distributários do Rio Nilo, o termo Delta sofreu sucessivas modificações em sua definição para acomodar cada nova descrição de acumulações costeiras associadas a desembocaduras fluviais (veja revisão histórica em LeBlanc 1975). Esta tendência culminou com o trabalho clássico de Fisher et al. (1969), no qual o termo delta foi definido com "a river-fed depositional system that results in irregular progradation of a shore line". Wright (1978) definiu delta como "coastal accumulation, both subaqueous and subaerial, of river-derived sediments adjacent to, or in close proximity to, the source stream, including the deposits that have been secondarily molded by various marine agents, such as waves, currents or tides". Como resultado, hoje pode ser chamada de delta, virtualmente, qualquer acumulação costeira. $O$ único requisito básico é a associação geográfica desta acumulação costeira com uma desembocadura fluvial. Estas definições extremamente genéricas, refletindo a preocupação dos autores em formularem-nas de modo a dar-lhes uma aplicação universal, nas quais pudessem ser enquadradas diferentes categorias de objetos, trazem em si uma grande desvantagem, ou seja, a de revelarem uma forte influência de natureza semântica. Conforme observa Marcos (1982), o neófito ao deparar-se com uma terminologia desta natureza irá provavelmente, na busca da compreensão do objeto estudado, aceitar sem questionamento os termos e pro-
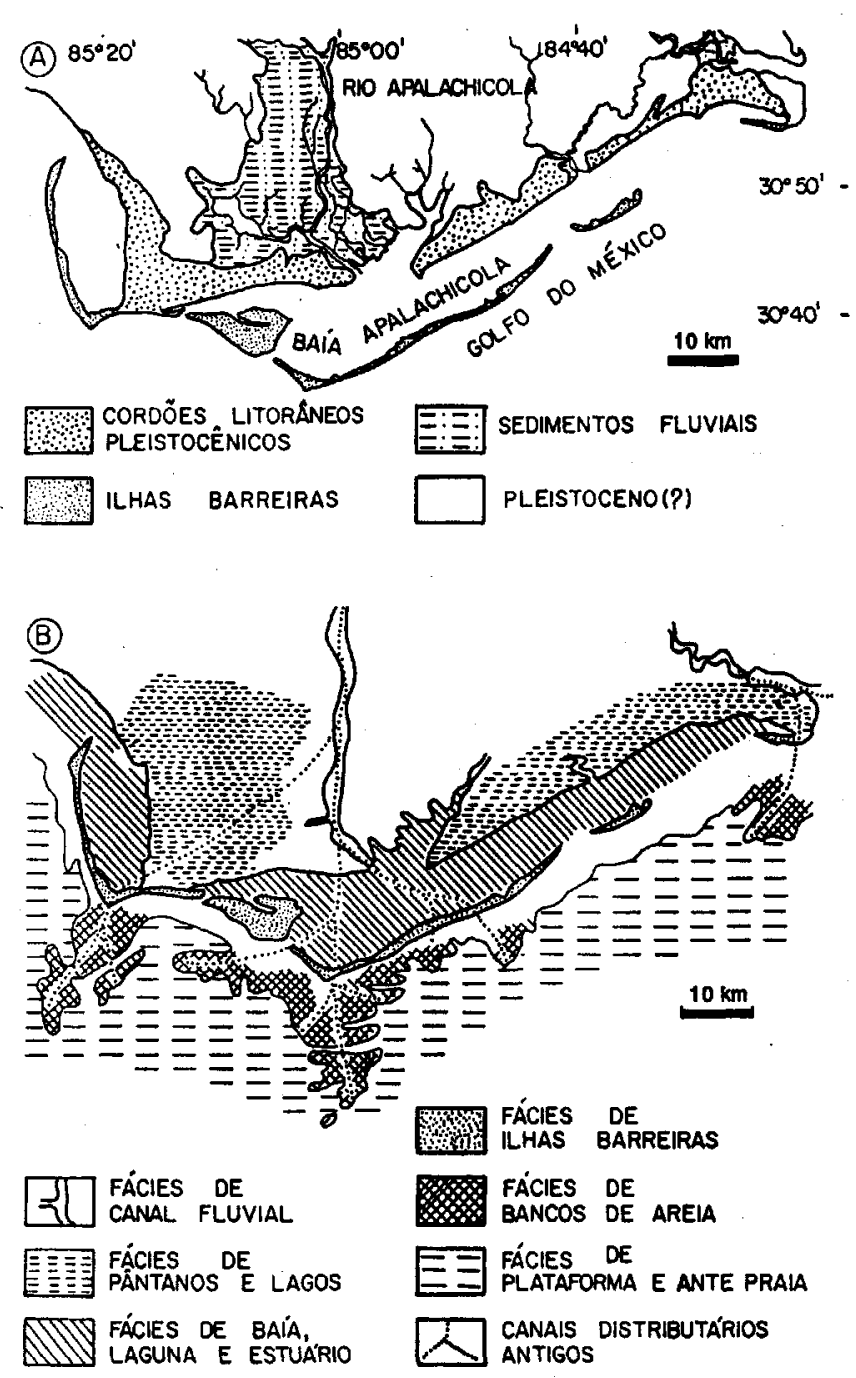

Figura 4 - A. Mapa geológico simplificado da zona costeira associada à desembocadura do Rio Apalachicola (modificado de Schnable \& Goodell 1968); B. Principais ambientes de deposição do sistema deltaico do Rio Apalachicola, segundo Fisher (1969) (modificado deste autor). Veja texto para discussão

Figure 4 - A. Simplified geologic map of the coastal zone associated with the Apalachicola river mourn (modified from Schnable \& Goodell 1968); B. Depositional environments of the Apalachicola river deltaic system according to Fisher (1969) (modified from this author). See text for discussion

curar perceber neste objeto de estudo o que os termos sugerem, resultando na total inversão do método científico. Dessa forma, o iniciado tenderá a adotar o método da teoria dominante, no qual a teoria ou as explicações dominam os fatos (Marcos 1982).

No que concerne à sedimentação deltaica, a apUcação não crítica das definições extremamente amplas, ora em uso, resultaram em apriorismo e circularidade de argumentos do tipo: uma acumulação costeira é classificada como um delta porque está associada a um desembocadura fluvial, então, - porque é um delta -, a principal fonte de sedimentos para a progradação da linha de costa é de origem fluvial (e.g. alimentação transversal). Esse tipo de argumentação é exemplificado em Balsley (1983, p. 16-24) em seu estudo de seqüências de arenitos costeiros da Formação Blackhawk na área de Book CUffs (Estado de Utah, Estados Unidos da América): "In their re- 
gional setting along the western margin of the Interior Seaway, most of the sand bodies are located down the depositional slope from the fluvial coastal plain and directly adjacent to the marine environment. In seaward and downward directions, the sands grade into Mancos Shale of inferred prodelta origin. The paleogeographic location of the sand bodies and their association with major shoreline regression suggest a deltaic origin". Observe, neste caso, que Balsley (1983) concluiu que os arenitos costeiros da Formação Blackhawk são de origem deltaica apenas pela localização paleogeográfica desses arenitos (apriorismo), ou seja, ele não se preocupou em estabelecer se os sedimentos são de fato originários dos sistemas fluviais adjacentes, para então concluir se se trata realmente de um delta. Intrínseca nessa argumentação existe uma boa dose de circularidade de raciocínio qual seja; os arenitos costeiros apresentam alimentação transversal porque são de origem deltaica. Tal argumentação nem sempre é válida, particularmente no que concerne às planícies costeiras quaternárias discutidas neste trabalho.

Vamos considerar inicialmente um caso simples no qual as frentes de ondas se aproximam paralelamente à linha de costa. Em presença de uma fonte pontual de sedimentos (e.g. desembocadura fluvial), as ondas irão distribuir os sedimentos fluviais para ambos os lados da desembocadura. Uma acumulação sedimentar em forma de cúspide será depositada associada à desembocadura fluvial (Fig. 5a). Esta é provavelmente uma situação extremamente rara no registro geológico. Mais comumente, deve-se esperar que as frentes de ondas formem um ângulo agudo com a linha de costa. Nesta situação, o efluente fluvial irá atuar como um molhe retendo a barlamar (updrijf) da desembocadura fluvial os sedimentos transportados pela deriva litorânea ("Efeito de Molhe", Dominguez et al. 1983, Martin et al. 1985) (Fig. 5b). A sotamar (downdrift) da desembocadura, a linha de costa será alimentada pelos sedimentos trazidos pelo rio. Zenkovitch (1967) relata o mesmo fenômeno para desembocaduras fluviais situadas ao longo da costa do Mar Negro. Komar (1973), usando simulação por computadores, também concluiu que desembocaduras fluviais atuam como barreiras à deriva litorânea de sedimentos, comportando-se efetivamente como molhes.

A aplicação das definições de sistemas deltaicos atualmente em uso, para situações como as descritas acima, resultará no contra-senso de se denominar de delta apenas a porção da planície costeira situada a sotamar da desembocadura fluvial, tendo em vista ser este o local onde os sedimentos fluviais são depositados após terem sido retrabalhados pela ação das ondas.

Outra conseqüência importante do "Efeito de Molhe" é que diferentes modos de progradação irão caracterizar as porções da planície costeira situadas a sotamar e a barlamar da desembocadura fluvial (Fig. 5b). Na porção da planície costeira situada a barlamar da desembocadura, os sedimentos trazidos pela deriva litorânea são continuamente incorporados ao prisma de praia, resultando no avanço da linha de costa. O resultado final é um lençol contínuo de areias litorâneas, capeadas por depósitos de cordões litorâneos (Fig. 5b). Na porção da planície costeira situada a sotamar da desembocadura fluvial, as ondas retrabalham as barras de desembocadura dando origem a ilhas arenosas e esporões. Estas ilhas arenosas e esporões, ao se estenderem longitudinalmente, dão origem a pequenas lagunas, as quais são rapidamente preenchidas por sedimentos argilosos de origem fluvial. $O$ resultado final deste estilo de progradação é uma sucessão de corpos arenosos lineares separados uns dos outros por zonas baixas pantanosas. Essa diferença nos modos de progradação entre os lados a sotamar e a barlamar da desembocadura fluvial foi observada nas planícies costeiras associadas às desembocaduras dos Rios São Francisco, Jequitinhonha e Paraíba do Sul (Dominguez et al. 1983).

Datações pelo método do radiocarbono de cordões litorâ- neos holocênicos è outras feições geomórficas indicam que as taxas de progradacao'da porção da planície costeira situada a barlamar da desembocadura fluvial nos Rios Jequitínhonha e Paraíba do Sul são, respectivamente, 2 e 1,5 vezes maiores que aquelas observadas na porção da planície costeira situada a sotamar da desembocadura (Dominguez et al. 1983). Para o Rio São Francisco, taxas semelhantes de progradação foram observadas para ambos os lados da desembocadura fluvial (Dominguez et al. 1983). Dessa forma, para estas planícies costeiras, o volume de sedimentos fornecido pela deriva litorânea (alimentação longitudinal) é maior que, ou pelo menos equivalente, ao volume de sedimentos fornecidos pelo rio (alimentação tranversal).

Uma forte deriva litorânea pode ainda forçar uma migração intermitente da desembocadura no sentido de sotamar, como foi observado nas planícies costeiras dos Rios Paraíba do Sul e Jequitinhonha (Dominguez et al. 1983). A figura 6 ilustra o mecanismo envolvido nessa migração (Martin et al. 1985).

Durante períodos de alta descarga fluvial, o rio se comporta efetivamente como um molhe interrompendo a deriva litorânea de sedimentos. A linha de costa na porção da planície costeira situada a barlamar da desembocadura então prograda (Fig. 6a). Durante períodos de baixa descarga fluvial ou estiagem, o "efeito de molhe" do rio é menos efetivo. A linha de costa a barlamar da desembocadura irá então experimentar erosão. Os sedimentos erodidos serão modelados em um es-

\section{EFEITO DE MOLHE}
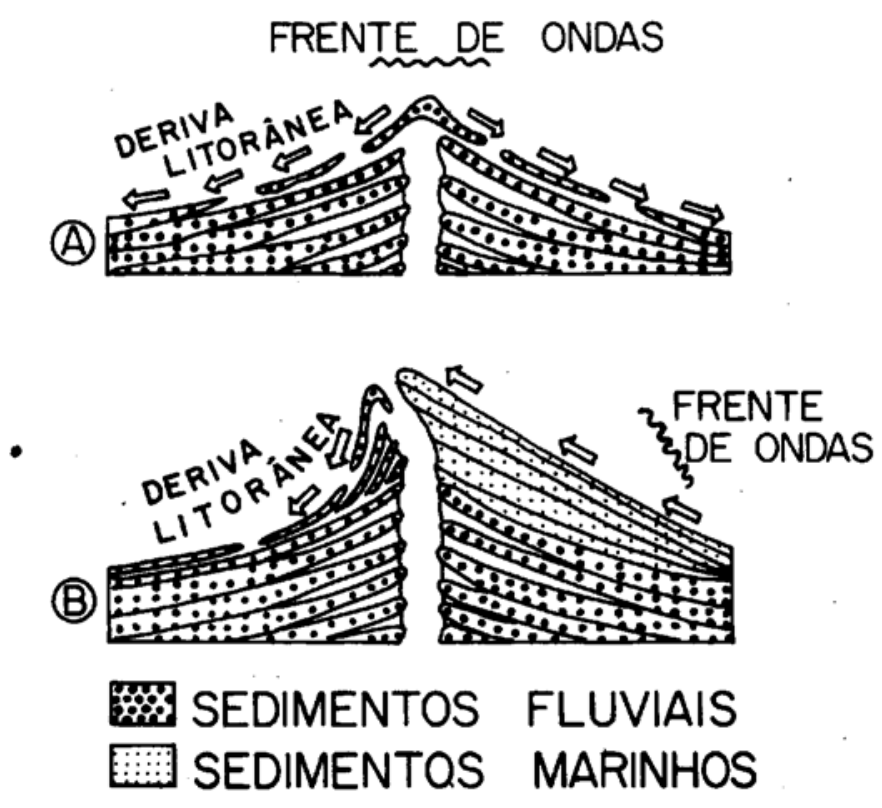

Figura 5 - "Efeito de Molhe". A. quando as frentes de onda se aproximam paralelamente à costa, estas irão distribuir os sedimentos fluviais para ambos os lados da desembocadura; B. quando as frentes de onda formam um angulo agudo com a linha de costa o efluente fluvial irá atuar como um molhe retendo a barlamar da desembocadura fluvial os sedimentos transportados pela deriva litorânea. A sotamar da desembocadura a linha de costa será alimentada pelos sedimentos trazidos pelo rio

Figure 5 - "The Groin Effect". A. When the wave fronts approach parallel to the shoreline, the longshore drift will redistribute fluvial sediments to both rides of the river mouths; B. When the wave fronts approach the shoreline forming and angle, the fluvial discharge will act as a groin retaining updrift of the river mourn those sediments transported by the wave-induced longshore drift. Riverbome sediments will accumulate downdrift of the river mouth 

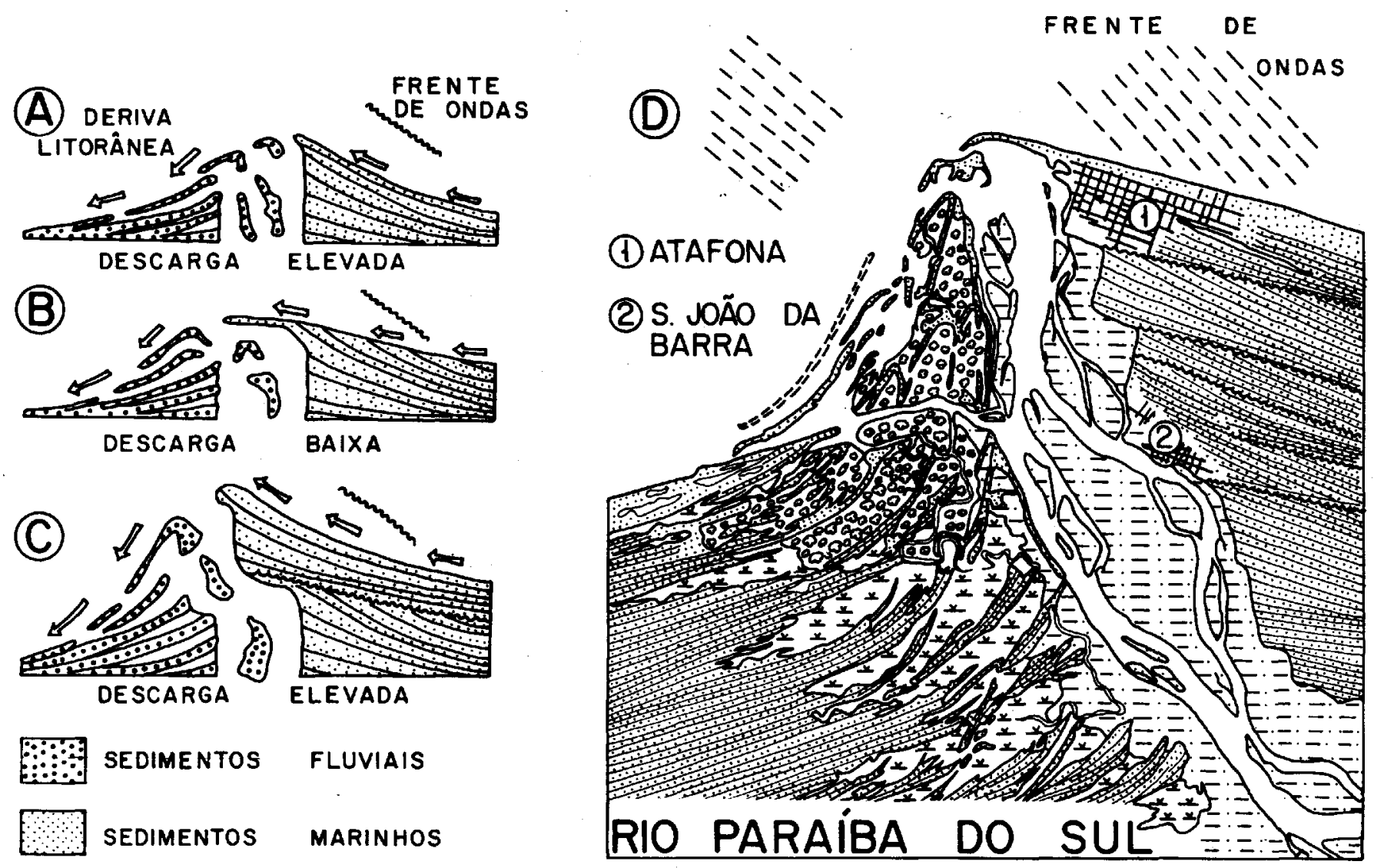

Figura 6- A, B e C. Esquema mostrando mecanismo de migração intermitente da desembocadura fluvial no sentido de sotamar. Esta migração resulta da interação entre a deriva litorânea e flutuações na descarga fluvial. D. Mapa geológico das vizinhanças da desembocadura do Rio Paraíba do Sul. O mapa mostra claramente o padrão escalonado com truncamentos erosivos para os cordões litorâneos situados a barlamar da desembocadura fluvial (modificado de Martin et al. 1985). Veja figura l para legenda, e texto para maiores detalhes

Figure 6 - A, B and C. Scheme showing mechanism of downdrift intermittent migration of the river mouth. This migration results of the interaction between the longshore drift and fluctuations in fluvial discharge; D. Geologic map of the region around the Paraíba do Sul river mouth. The map clearly shows the erosive truncations of beach-ridges updrift of the river mouth (modified from Martin et al. 1985). See Figure 1 for legend and text for details

porão arenoso, que obstrui parcialmente a desembocadura fluvial, forçando-a a ocupar uma nova posição, ligeiramente a sotamar (Fig. 6b). No próximo período de descarga elevada, o efluente fluvial irá novamente atuar como um molhe, interrompendo a deriva litorânea de sedimentos. Em conseqüência, a progradação será retomada na porção da planície costeira situada a barlamar da desembocadura fluvial (Fig. 6c). A repetição desses processos resultará em um padrão escalonado com truncamentos erosivos, para os cordões litorâneos situados a barlamar da desembocadura fluvial (Fig. 6c). Este padrão é muito bem ilustrado na desembocadura do Rio Paraíba do Sul (Fig. 6d).

Um caso extremo do mecanismo descrito acima é exemplificado pelo Rio Senegal (Fig. 7). Nessa região, uma forte deriva litorânea força a desembocadura fluvial a migrar continuamente no sentido de sotamar. Sedimentos fluviais numa situação como esta serão depositados bastante afastados da desembocadura fluvial.

Na planície costeira associada à desembocadura do Rio Senegal, a barreira arenosa e os depósitos praiais usados para classificar esta área como um delta dominado por ondas, não possuem nenhuma relação com o rio propriamente dito. Ao contrário, estes sedimentos foram trazidos pela deriva litorânea a partir da erosão de depósitos eólicos pré-holocênicos localizados a barlamar da planície costeira (Michel 1968).
Apesar da importância da alimentação longitudinal em ambientes dominados por ondas, Coleman \& Wright (1975, p. 112) enfatizaram apenas o papel desempenhado pela deriva litorânea no desenvolvimento de topografia rítmica e estratificação cruzada em areias litorâneas.

CICLOS DELTAICOS: AUTOCICLICIDADE VERSUS ALOCICLICIDADE $O$ conceito de ciclos deltaicos foi primeiramente introduzido por Scruton (1960) e depois expandido por Coleman \& Gagliano (1964). De acordo com esse conceito, deltas raramente constróem indefinidamente em uma única direção. Progradação contínua de um delta aproximadamente ao nível do mar resulta em um decréscimo progressivo no gradiente do sistema distributário. O rio muda então para uma rota mais curta e de gradiente mais acentuado. Esta mudança na fonte pontual de suprimento de sedimento resulta no abandono de um delta ativo e o início de um segundo ciclo de sedimentação deltaica, associado à nova posição da fonte pontual de sedimentos. $\mathrm{O}$ delta abandonado, privado do suprimento de sedimentos, experimenta recuo da linha de costa e inundação, devido aos efeitos combinados da compactação e subsidência em associação com retrabalhamento dos sedimentos por correntes marinhas e por ondas. O mecanismo descrito acima é denominado de autocíclico, porque ele se auto-regula e se auto-perpetua, excluindo a necessidade de 
um mecanismo forçador externo (e.g. pulsos de subsidência da bacia, mudanças no nível do mar, mudanças no suprimento de sedimentos) para explicar a ciclicidade em sistemas deltaicos. Embora este modelo tenha sido originalmente desenvolvido para o delta do Rio Mississipi, o mesmo tem sido aplicado indiscriminadamente para interpretar ciclicidade em todos os sistemas de acumulação costeira associados a desembocaduras fluviais. Também aqui a circularidade de argumentos prevalece: como as acumulações costeiras discutidas neste trabalho são consideradas deltas, por causa de sua associação como uma desembocadura fluvial, então o modelo autocíclico descrito acima deve ser aplicável. Exemplos deste tipo de argumentação são encontrados em Weise (1980, p.25) e Balsley $(1983$, p.42).

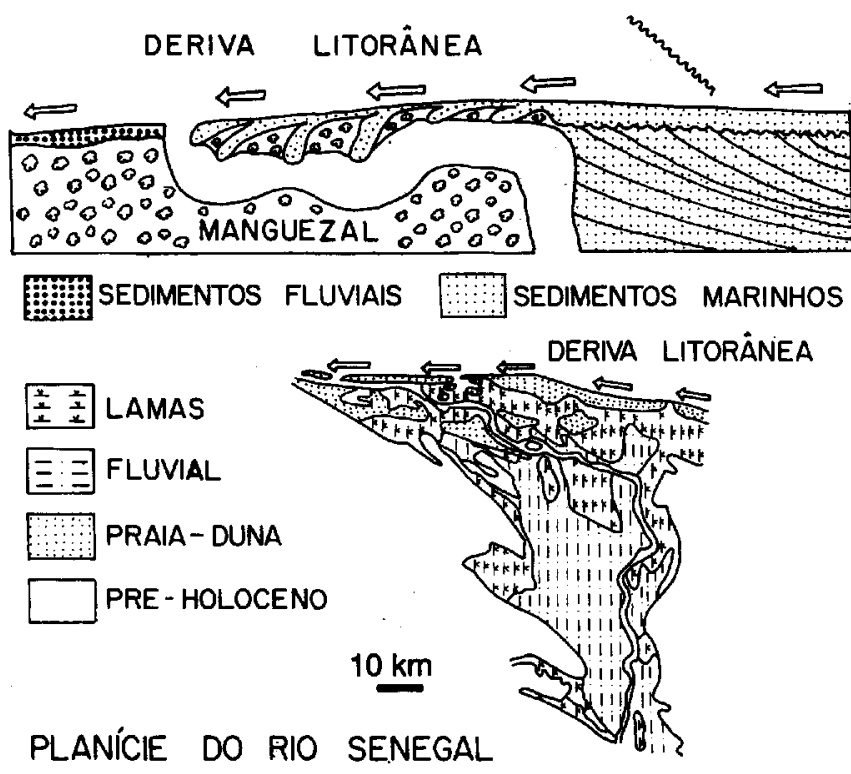

FRENTE DE ONDAS

Figura 7 - Migração contínua da desembocadura fluvial no sentido de sotamar em áreas caracterizadas por forte deriva litorânea, exemplificada pela planície do Rio Senegal (mapa geológico modificado de Michel 1968)

Figure 7 - Continuous downdrift migration of the river mourn in regions characterized by strong longshore drift, as exemplified by the Senegal river plain (geologic map modified from Michel 1968)

Ao longo da costa leste do Brasil, mudanças no curso inferior dos rios durante o Holoceno foram observados na planície costeira associada à desembocadura do Rio Jequitinhonha. Essas mudanças não resultaram de processos autocíclicos, mas de uma resposta a fatores externos (isto é, variações do nível do mar). Análise detalhada de sistemas de cordões litorâneos, presentes na planície costeira quaternária do Rio Jequitinhonha, revelou a existência de três conjuntos de cordões litorâneos, cada um associado com uma antiga posição de desembocadura fluvial. Dominguez (1982) concluiu, baseado em evidências morfológicas e em datações de cordões litorâneos e depósitos fluviais pelo método do radiocarbono, que os três sistemas de cordões litorâneos foram depositados durante as três fases de emersão da curva de variações do nível do mar (Figs, 1 e 8). As fases de submersão 2 e 3 (Figs, 1 e 8) causaram afogamento da desembocadura fluvial e induziram mudanças no curso inferior dos rios por meio de um processo do tipo avulsão. Nas novas desembocaduras ocupadas, a progradação foi retomada durante as fases de emersão subseqüentes. Dessa forma, a planície costeira do Rio Jequitinhonha oferece um exemplo no qual mudanças no curso inferior dos rios não resultaram de processos autocíclicos. Ao contrário, tais mu- danças foram induzidas por um fator externo (variações do nível do mar).

CONSIDERAÇÕES FINAIS As definições muito amplas de sistemas deltaicos em uso atualmente resultaram no agrupamento sob um mesmo nome (delta), de acumulações costeiras exibindo características bastante variadas e que apresentam em comum apenas o fato de estarem associadas geograficamente a uma desembocadura fluvial. Na ocasião em que estes modelos de sedimentação deltaica foram desenvolvidos, muitas das áreas-tipo eram pouco conhecidas, particularmente aquelas que recebiam os modificadores "dominado por ondas" e "dominado por marés". Inevitavelmente, fenômenos descritos para áreas muito bem estudadas como o delta do Rio Mississipi (e.g. alimentação transversal, autocicicidade) foram não-criticamente extrapolados e presumidos serem também válidos para todas as outras acumulações costeiras agrupadas sob o termo "delta".

Conforme discutido neste trabalho, dois importantes aspectos necessitam ser incorporados aos modelos existentes. Primeiro, as variações do nível do mar durante o Quaternário desempenharam um importante papel na evolução das regiões costeiras. Este papel foi completamente ignorado ou não foi incorporado de maneira apropriada na formulação dos modelos existentes de sedimentação deltaica. Isto aconteceu provavelmente devido a uma crença generalizada e de acordo com a qual o nível do mar teria subido continuamente em todo o globo durante os últimos $5 \mathrm{ka}$. Como discutido anteriormente, é virtualmente impossível se entender a distribuição de fácies e evolução de áreas costeiras sem um conhecimento prévio da história de variações do nível do mar. Adicionalmente, subidas rápidas do nível do mar, como aquelas documentadas para a costa leste do Brasil durante o Holoceno, constituiram um importante mecanismo forçador para mudanças no curso inferior dos rios (alociclicidade).

Em segundo lugar, um volume significativo de sedimentos para a progradação da linha de costa pode ser fornecido pela deriva litorânea gerada por ondas (alimentação longitudinal). $\mathrm{O}$ efluente fluvial funciona como um molhe, retendo a barlamar da desembocadura fluvial os sedimentos transportados pela deriva litorânea ("efeito de molhe"). Os sedimentos de origem fluvial (alimentação transversal) irão alimentar apenas a porção da planície costeira situada a sotamar da desembocadura.

Sugere-se portanto que o termo "delta" tenha a sua aplicação restrita àquelas regiões como o delta do Rio Mississipi, onde o rio verdadeiramente exerce um papel importante na distribuição de fácies e evolução da planície aluvial. É certo que muitos apresentarão resistências a esta contestação de conceitos estabelecidos, uma vez que esses conceitos, elaborados ao longo do tempo, não são tão facilmente abandonados. Entretanto, é necessário que se perceba que uma definição, como bem lembrado por Marcos (1982), representa uma tentativa de determinar e estabelecer os limites e a natureza de um objeto, indicando suas características distintivas. Se insistirmos em classificar as áreas costeiras aqui discutidas como deltas, o termo "delta" deve então, ser redefinido à luz das informações aqui apresentadas. Assim, a definição de Fisher et ai. (1969) poderia ser modificada da seguinte maneira: Delta é um sistema deposicional associado a uma desembocadura fluvial, alimentado por diversas fontes de sedimentos, e que resulta na progradação irregular da Unha da costa. Do mesmo modo, a definição proposta por Wright (1978) poderia ser assim expressa: delta é uma acumulação costeira de sedimentos oriundos de diversas fontes, adjacente ou em estreita proximidade a um efluente fluvial, incluindo os depósitos modelados por agentes marinhos, vento e gelo. Como tais modificações contrariam o espírito com que o termo "delta" foi originalmente utilizado por Heródoto ("O Egito é um presente do Nilo"), ou como foi definido de forma precisa por Barrei 
FASE DE SUBMERSÃO I $-5,1 \mathrm{ka}$

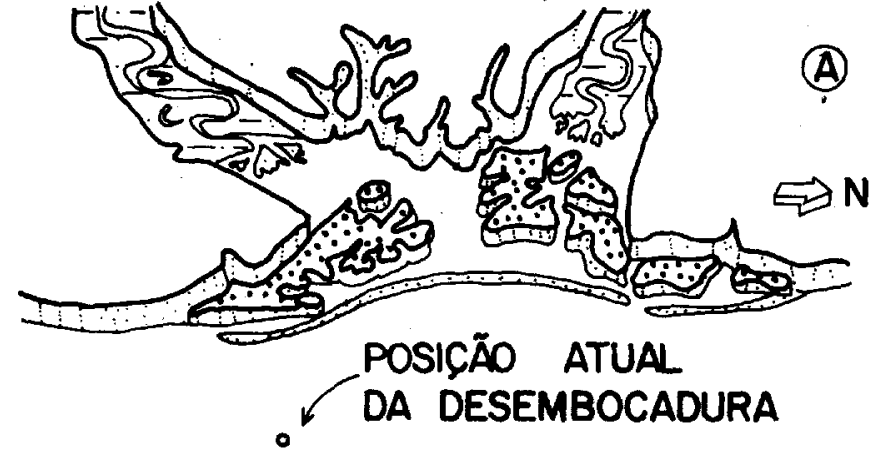

FASE DE SUBMERSÃO II $-3,8 / 3,5 \mathrm{ka}$

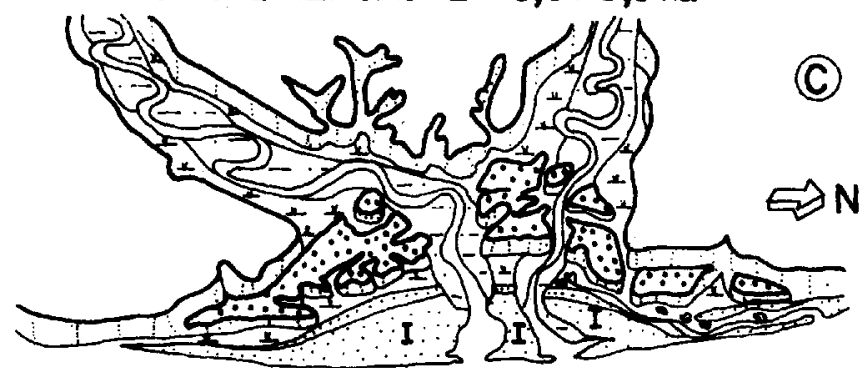

o

FASE DE SUBMERSÃO- 2,7/2,5 ka

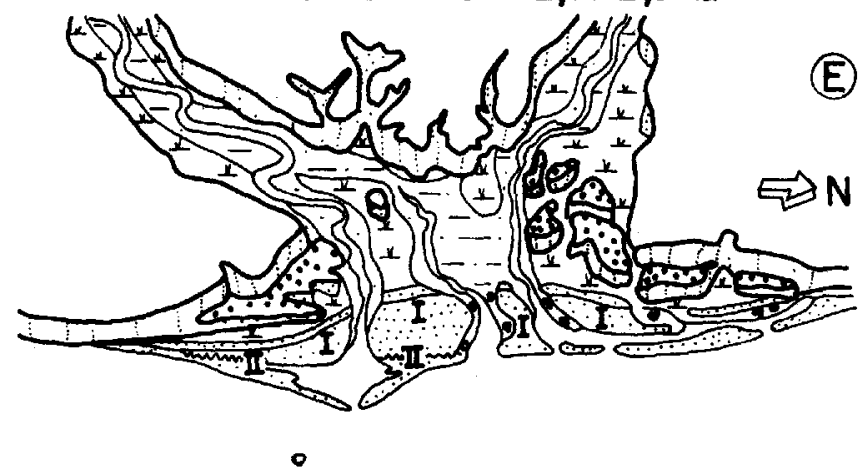

$\because \because$ MANGUE

* * PÁNTANO de ÁgUa doce

二:ニ. FLUVIAL
FASE DE EMERSÃO I - 5,1/3,8 ka

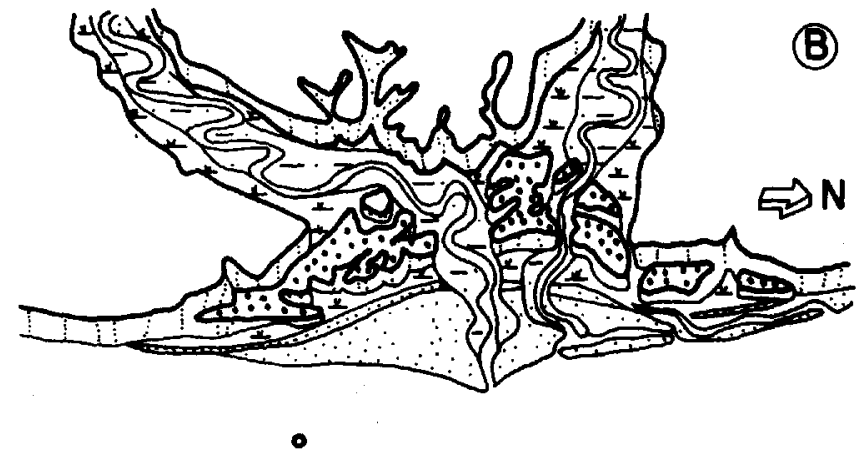

FASE DE EMERSÃO II - 3,5/2,7 ka

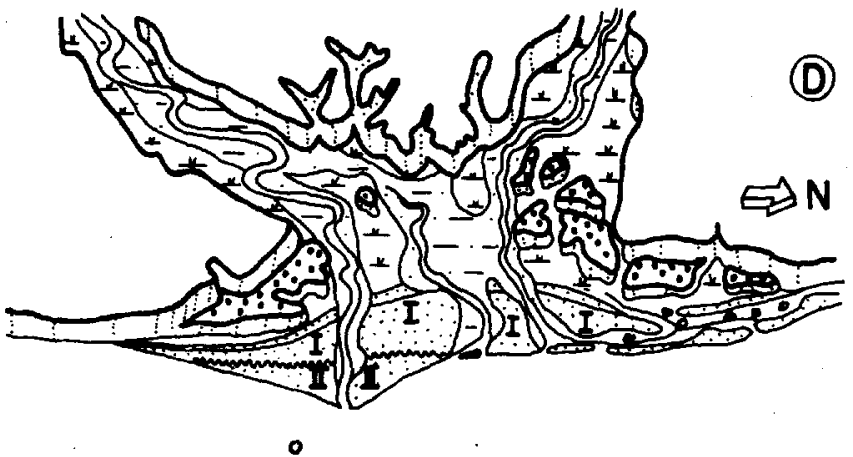

FASE DE EMERSÃO III - 2,5ka ATÉ O PRE -

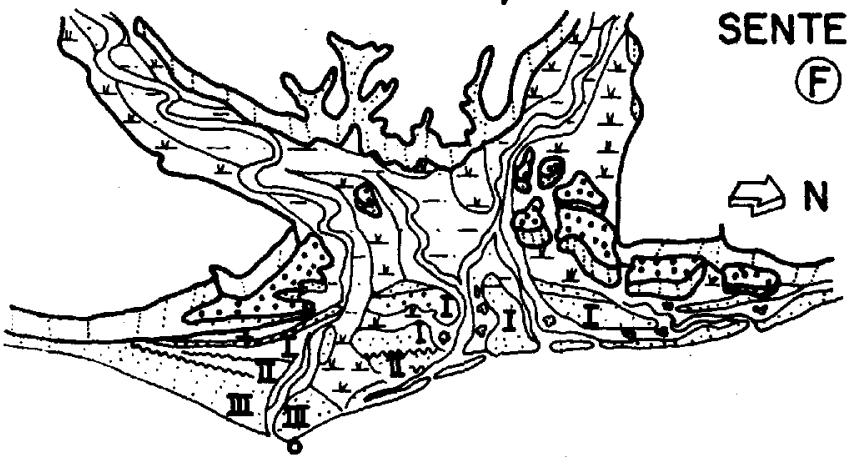


(1912) ("a deposit partly subaerial built by a river into or against a body of permanent water") é, portanto, altamente recomendável que este termo seja abandonado para descrever planícies costeiras associadas a desembocaduras fluviais em ambientes dominados por ondas. Dominguez et al. (1982) e Suguio et al. (1982), inclusive, já haviam proposto anteriormente que o termo "delta" não fosse utilizado para designar as zonas de progradação associadas as desembocaduras dos grandes rios que deságuam na costa leste do Brasil.

Até o presente momento a aplicação do termo "delta" a ambientes dominados por ondas, tais como aqueles discutidos neste trabalho, resultou em uma série de concepções errôneas que constituíram um grande obstáculo ao entendimento da evolução dessas áreas (Dominguez 1986). Chamar estas áreas simplesmente de deltas contribuiu apenas para interromper a inquirição científica e neglicenciar a riqueza dos processos envolvidos na história evolutiva das mesmas.

Finalmente, e em relação a este aspecto, é oportuno citar o seguinte trecho extraído de Curray et al. (1967), publicado antes da formulação dos modelos de sedimentação aqui discutidos, relativo ao seu estudo da planície costeira de Nayarit (México), a qual é muito similar as planícies de cordões litorâneos presentes na costa leste do Brasil: "The Nayarit coastal plain is a many faceted problem. It can be considered a type of delta, or a type of barrier, lagoon, strandplain coast. It can be studied as an example of the turning point from transgression to regression. It can be used as a modern model for deposition of regressive sheet sands so important in the geological record".

Na literatura geológica, a planície costeira de Nayarit é usualmente referida como um exemplo clássico de areias litorâneas regressivas (e.g. Reineck \& Singh 1980). Se esta área tivesse sido estudada nos dias atuais teria sido prontamente classificada como um delta dominado por ondas. Apriorismo e raciocínio circular se encarregariam rapidamente de identificar uma frente deltaica, pró-delta, barras de desembocadura e ciclos deltaicôs. Como resultado, os múltiplos aspectos da história daquela planície teriam sido facilmente negligenciados.

Agradecimentos $\mathrm{O}$ autor agradece ao Conselho Nacional de Desenvolvimento Científico e Tecnológico (CNP.q) pela Bolsa de Pesquisador. Os drs. Donald Moore (RSM AS-University of Miami) e Randall Parkinson (RSMAS-University of Miami) ofereceram valiosas críticas a uma versão preliminar deste trabalho.

\section{REFERÊNCIAS BIBLIOGRÁFICAS}

BALSLEY, J.K. 1983. Cretaceous wave-dominated delta systems: Book Cüffs, East Central Utah. Oklahoma, Geol. Soc. 219p. (Guia de Campo).

BARREL, J. 1912. Criteria for the recognition of ancient delta deposits Geol. Soc. America BuU., 23:377-446.

CHAMBERLIN, T.C. 1965. The method of multiple working hypothesis. Science, 148:754-759.

CHAPELL, J. 1974. Late Quaternary Glacio and Hydro-isostasy, on a layered Earth. Quaternary Research, 4:429-440.

CLARK, J.A.; PARREL W.E.; PELTIER, W.L. 1978. Global changes in post-glacial sea-level: a numerical calculation. Quaternary Research, 9:265-287.

COLEMAN, J.M, \& GAGLIANO, S.M. 1964.Cyclic sedimentation in the Mississipi river deltaic plain. Gulf Coast Assoc. Geol. Socs. Trans., 14:67-80.

COLEMAN, J.M. \& WRIGHT, L.D. 1971. Analysis of major river systems and their deltas: procedures and rationale, with two examples. Louisiana State Univ., Coastal Studies Inst. Tech. Rept. examples.

COLEMAN, J.M. \& WRIGHT, L.D. 1975. Modem river deltas: variability of processes and sandstones bodies. In: BROUSSARD, M.L. ed. Deltas, Models for Exploration. Houston, Geol. Soc. p.99-150

CURRAY, J.R.; EMMEL, FJ.; CRAMPTON, PJ.S. 1967. Holocene history of a strandplain, lagoonal coast, Nayarit Mexico. In: CASTENARES, A.A.; PHELGER, F.B., eds. Lagunas Costeiras Um Simpósio. Universidad Nacional Autônoma de México, p. 63-100.

DOMINGUEZ, J.M.L. 1982. Evolução quaternária da planície costeira do Rio Jequitinhonha (BA): influencia das variações do nivel do mar e da deriva litorânea de sedimentos. Salvador, 79p. (Dissertação de Mestrado, Instituto de Geodências, UFBa).

DOMINGUEZ, J.M.L. 1984. Sealevel hystory: a dominant control on modera coastal sedimentation styles (resumo). In: FIRST ANNUAL MIDYEAR MEETING. San Jose, California, Soc. Econ. Paleon. and Mineral, p.26.

DOMINGUEZ, J.M.L. 1986. Re-evaluation of deltaic sedimentation models in wave-dominated settings, evidences from eastern Brazil (resumo). Geol. Soc. Amer., 18:586-587. (Abstracts with Programs).

DOMINGUEZ, J.M.L.; BITTENCOURT, A.C.S.P.; MARTIN, L. 1981. Esquema evolutivo da sedimentação quaternária nas feicões deltaicas dos Rios Sio Francisco (SE/AL), Jequitinhonha (BA), Doce (ES) e Paraíba do Sul (RJ). Rev. Bras. Geoc., 11:227-237.

DOMINGUEZ, J.M.L.; BITTENCOURT, A.C.S.P.; MARTIN. L.. 1983. O papel da deriva litorânea de sedimentos arenosos na construç\&o das planícies costeiras associadas às desembocaduras dos Rios São Francisco (SE/AL), Jequitinhonha (BA), Doce (ES) e Paraíba do Sul (RJ). Rev. Bras. Geoc., 13:98-105.

DOMINGUEZ, J.M.L.; MARTIN, L.; BITTENCOURT, A.C.S.P. 1987. Sealevel history and Quaternary evolution of river mouth-associated beach-ridge palins along the eastern/southeastern Brazilian coast: a summary. In: NUMMEDAL, D.H.; PILKEY, O.; HOWARD, J.D., eds. Sea-level Fluctuation and Coastal Evolution. Soc. Econ. Paleont. Mineral. 41:115-127. (Publicação Especial).

DOMINGUEZ, J.M.L.; MARTIN, L.; BITTENCOURT, A.C.S.P.; FERREIRA, Y.A.; FLEXOR, J.M. 1982. Sobre a validade da utilização do termo delta para designar as planícies costeiras associadas às desembocaduras dos grandes rios da costa leste/nordeste brasileira. In: CONOR. BRAS. GEOL., 32, Salvador, 1982. Resumos e Breves Comunicações... Salvador, SBG.p.92.

FAURE, H. \& HEBRARD, L. 1973. Variations dês lignes de rivage au Senegal et en Mauritaine au cours de l'Holocene. In: BLOOM, A.L., ed. Adas of Sea Level Curves. 61:D18. (IGCP Project).

FISHER, W.L. 1969. Fades characterization of Gulf coast basin delta systems, with some Holocene analogues. Gulf Coast Assoc. Geol. Soc. Trans., 19:239-261.

FISHER, W.L.; BROWN Jr., L.F.; SCOTT, A J.; McGOWEN, J.H. 1969. Delta systems in the exploration of oil and gas. Bureau of Economic Geology, Univ. do Texas. 212p.

GALLOWAY, W.E. 1975. Process framework for describing the morphologic and stratigraphic evolution of deltaic depositional systems. In: BROUSSARD, M.L., ed. Deltas: Models for Exploration. Houston, Geol. Soc. p. 87-98.

HEWARD, A.P. 1981. A review of wave-dominated clastic shoreline deposits. Earth-Sd. Rev., 17:223-276.

KIDSON, C. 1982. Sealevel changes in the Holocene. Quaternary Sd. Rev., 1:121-151.

KOMAR, P.D. 1973. Computer models of delta growth due to sediment input from riven and longshore transport. Geol. Soc. America BuU., 84:2217-2226.

LeBLANC, R J. 1975. Significant studies of modem and ancient deltaic sediments. In. BROUSSARD, M.L. ed. Deltas: Models For Exploration. Houston Geol. Soc. p. 13-85.

MARCOS, Z.Z. 1982. Ensaio sobre epistemologia pedològica. Cah. OJRJS.T.OM., XIX:5-28. (Serie Pédologie)

MARTIN, L.; SUGUIO, K.; FLEXOR, J.M.; BITTENCOnRT A.C.S.P.; VILAS BOAS, G.S. 1980. Le Quateraaire marin bresilien (littoral pauliste, sud-fluminense et bahianais). Cah. OXS.T.OM. XI:95-124. (Serie Geologic).

MARTIN, L.; SUGUIO, K.; FLEXOR, J.M.; TESSLER, M.; EICHLER, B.B. 1985. Roundness in Holocene sands of the Paraíba do Sul coastal plain, Rio de Janeiro, Brazil. Joum. Coastal Research, 1:343-351.

MICHEL, P. 1968. Gênese et evolution de la valles du Senegal, de Bakel a rembouchure (Afrique Occidentale). Zeitschrift Fur Geomorphohgie, 12:318-349.

MORNER, N.A. 1976. Eustasy and Geoid Changes. Journal of Geology, 84:123-15i.

NEWMAN, W.S.; MARCUS, L.F.; PARDI, R.R.; PACCIONE, J.A.; TOMECEK, S.M. 1980. Eustasy and deformation of the Geoid: 1000-6000 radiocarbon years B .P. In: MORNER, N.A., ed., Earth 
Rheology, Isostasy and Eustasy. Stockholm. 1977:555-567. (Proceedings of Symposium).

REINECK, H.E. \& SINGH, I.B. 1980. Depositional Sedimentary Environments. New York, Springer-Veriag. 439 p.

SCHNABLE, J.E. \& GOODELL, H.G. 1968. Pleistocene-Recent stratigraphy, evolution and development of the Apalachicola Coast, Florida, Geol. Soc. America. 112:72p. (Spec. Paper).

SCRUTON, P.C. 1960. Delta building and the deltaic sequence. In: SHEPARD, F.P.; PHLEGER, F.B.; VAN ANDEL, T.H., eds. Recent Sediments, Northwest Gulf of Mexico, a symposium. Amer. Assoc. Petroleum Geologists, p.82-102.

SUGUIO, K.; MARTIN, L; BITTENCOURT, A.C.S.P.; DOMINGUEZ, J.M.L.; FLEXOR, J.M. 1984. Quaternary emergent and submergent coasts: comparison of the Holocene sedimentation in Brazil and southeastern United States. AnAcad. bras. Cienc. 56:163-167.

SUGUIO, K.; MARTIN, L.; DOMINGUEZ, J.M.L. 1982. Evolução da planície costeira do Rio Doce (ES) durante o Quaternário: influência das flutuacões do nível do mar.In: SIMPOSIO DO QUATERNÁRIO DO BRASIL, 4, Rio de Janeiro. 1982. Aftw... Rio de Janeiro, p. 93-116.

SUGUIO, K.; MARTIN, L.; FLEXOR, J.M. 1980. Sealevel fluctuations during the past 6000 yean along the coast of the state of Sao Paulo (Brazil). In: MORNER, N.A. ed., Earth Rheology, Isostasy, and Eustasy. New York, Wiley \& Sons. p. 471-486.
WALCOTT', R.I. 1972. Past sea levels, Eustasy and deformation of the Earth. Quaternary Research, 2:1 -14.

WEISE, B.R. 1980. Wave-dominated delta systems of the Upper Cretaceous San Miguel Formation, Maverick Basin, South Texas. Bureau of Economic Geology, University of Texas. 39 p.

WRIGHT, L.D. 1978. River Deltas. Im DA VIS Jr., ed. Coastal Sedimentary Environments. New York, Springer-Veriag. p. 5-68.

WRIGHT, L.D. \& COLEM AN, J.M. 1972. River delta morphology wave climate and the role of the subaqueous profile. Science, 176:282-284

WRIGHT, L.D. \& COLEMAN, J.M. 1973. Variations in morphology of major river deltas as functions of ocean waves and river discharge regimes. Am. Assoc. Petroleum Geol. BuU., 57:370-398.

ZENKOVTTCH V.P. 1967. Process of Coastal Development. New York, Wiley \& Sons. 738p
MANUSCRITO D004

Recebido em 19 de março de 1990

Revisão em 25 de junho de 1990 Revisão aceita em 10 dejulho.de 1990 